\title{
The Safety of Medical Devices Used During Intraocular Surgery
}

\author{
J Carlos Pastor \\ Institute for Applied Ophthalmobiology, Campus Miguel Delibes, University of Valladolid, Valladolid, Spain
}

DOI: https://doi.org/10.17925/USOR.2020.13.2.73

$\mathrm{T}$ his review article summarizes the experience of the Retina Group at the Institute for Applied Ophthalmobiology, University of Valladolid, Spain. Different perfluorocarbon liquids used in intraocular surgery are discussed, as they have caused hundreds of cases of irreversible blindness in many countries since 2013. The possible causes are examined, and consideration is given to the current status and the measures that should be taken to prevent these situations from occurring in the future. Among these are: a greater awareness among ophthalmologists so they report suspected cases to their respective health agencies (medical devices office), without fear of legal reprisals by either government agencies or patients; a closer collaboration between expert clinicians and manufacturers on committees for the International Organization for Standardization in order to regulate each product individually; and the conducting of appropriate chemical and biological tests to guarantee the safety of the products.

\section{Keywords}

Toxicity, perfluorocarbon liquids, retina surgery, appropriate biological testing, reporting side effects

Disclosure: J Carlos Pastor has no financial or non-financial relationships or activities to declare in relation to this article. All the analyses were carried out by the mandate of the Spanish Agency for Medicines and Medical Devices (AEMPS), of which the Institute for Applied Ophthalmobiology is a collaborator.

Review Process: Double-blind peer review.

Compliance with Ethics: This article involves a review of the literature and did not involve any studies with human or animal subjects performed by the author.

Authorship: The named author meets the Internationa Committee of Medical Journal Editors (ICMJE) criteria for authorship of this manuscript, takes responsibility for the integrity of the work as a whole, and has given final approval for the version to be published.

Access: This article is freely accessible at touchOPHTHALMOLOGY.com (c) Touch Medical Media 2021.

Received: November 21, 2020

Accepted: December 21, 2020

Published Online: January 27, 2021

Citation: US Ophthalmic Review. 2021;13(2):73-5

Corresponding author: J Carlos Pastor, Institute for Applied Ophthalmobiology, Campus Miguel Delibes, Universidad de Valladolid, Avenida de Belén 17,

47011, valladolid, Spain. E: pastor@ioba.med.uva.es

Financial support: No funding was received in the publication of this article.
Since 2013, a series of acute ocular toxicity events have occurred, causing hundreds of cases of irreversible blindness. This has prompted the questioning of measures adopted by health regulatory bodies to approve the commercialization of certain products. ${ }^{1}$ The greatest problem is the use of perfluorocarbon liquids; however, cases of toxicity have occurred with other intraocular substances used in intraocular surgery (e.g. internal limiting membrane dyes and silicone oils). ${ }^{1}$ The reactions of the different actors involved have not always been the most appropriate; therefore, this paper outlines the steps required to prevent future occurrences.

On the one hand, there has been resistance among certain ophthalmologists to report suspicious cases to their national medicine agencies. This is due to the fear of legal reprisals possibly having an influence on their clinical activity. This may be due to the fact that some agencies, rather than considering that a product with a Conformité Européene (CE) marking is a cause of toxicity, assume that it is being misused by the ophthalmologist (oral communication, European Society of Retina Specialists (EURETINA) Congress, Paris, France, 5-8 September 2019).

On the other hand, some companies have reacted by denying the possibility that their products were the cause of the problem, attributing patient blindness to the product's misuse by surgeons, and not issuing alerts to all those countries where their products were distributed. ${ }^{2}$

Finally, there has been pressure from certain manufacturers, who have influenced the International Organization for Standardization (ISO) Standards Committees to establish safer limits of chemical purity. However, without reliable tests and a proven relation between these chemical limits and biological safety, they give the impression of being primarily interested in gaining a market share. At the Retina Group of Institute for Applied Ophthalmobiology (IOBA), University of Valladolid, we believe that safer limits will be achieved by close collaboration between clinicians and manufacturers, as well as full transparency from the companies regarding the origin of the raw materials, and a combination of appropriate and validated chemical and biological methods. ${ }^{3}$

One effect of this lack of collaboration has been the recent approval of a new ISO standard that refers to three types of product that have little relationship between them, other than the fact that they are used in vitreo-retinal surgery: intraocular gases, liquid perfluorocarbons, and silicone oils. Gases are generally used as temporary endotamponade agents, perfluorocarbon liquids as retinal manipulators or intrasurgical tools, and silicone oils as medium- and long-lasting vitreous substitutes. All of these substances appear in the ISO standard under the common term of "ophthalmic implants" or "ocular endotamponades," which makes it clear that there is no agreement among clinicians and manufacturers on the naming of products. ${ }^{3}$ 
Figure 1: Thirty days after successful retinal detatchment surgery

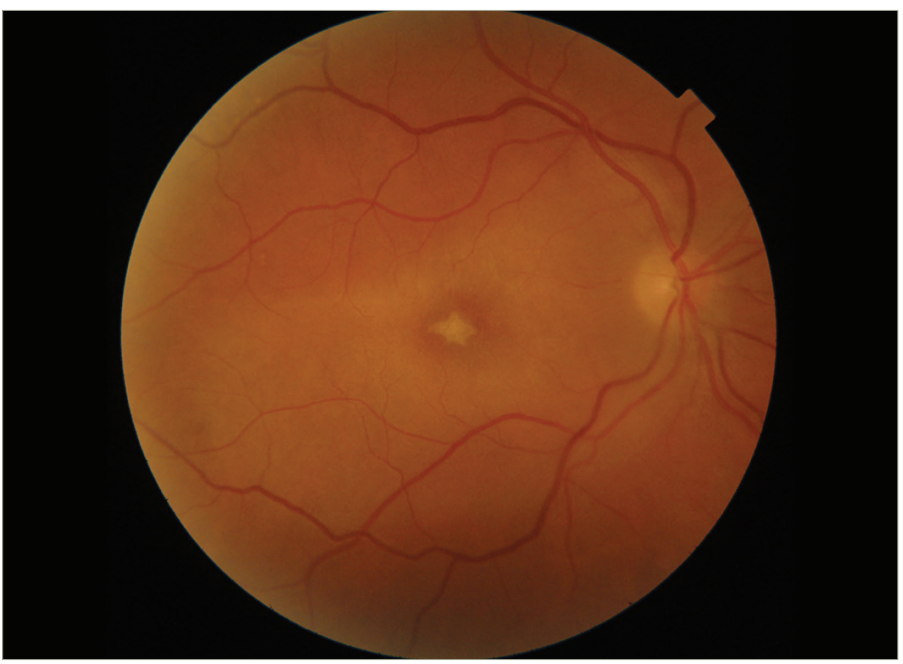

Visual acuity is 20/400. There is a pale area on the posterior pole, where perfluoro-octane was in contact during surgery. There is also subfoveal fibrosis.

The purpose of this study is to summarize the experience of the IOBA in this matter, encourage ophthalmologists and all healthcare personnel to declare suspicious cases, and prompt relevant health authorities to take the necessary measures so that adverse effects, such as that of liquid perfluorocarbons, are not repeated.

\section{The scandal of toxic perfluorocarbon liquids}

Perfluorocarbon liquids were introduced as retinal manipulators in the 1990s by Stanley Chang et al. ${ }^{4}$ The original idea was to be able to manipulate the retina, flattening it against the choroid and then allowing retinologists to apply laser as a retinopexy technique; hence its name "retinal manipulator," which many clinicians still use.

Despite their good degree of tolerance, it was soon evident that, if left inside the eye for long periods of time, perfluorocarbon liquids could often elicit serious inflammatory reactions. ${ }^{5}$ It has since been recommended that these liquids should be removed before concluding surgery. This is why some retinologists call them surgical tools, to reinforce that these substances should be used only during surgery.

Although these products, and mainly perfluoro-octane, have been used without any problem occurring in thousands of patients, in 2013 there were several cases of acute blindness caused by alleged retinal toxicity after correct use in uncomplicated surgeries, which related to one of these compounds. Four cases were reported to the Spanish Agency for Medicines and Medical Devices (AEMPS), together with several not-well-determined cases in Chile. The product was Meroctane ${ }^{\circledast}$ (Meran, Istanbul, Turkey). Recently, we collected sufficient clinical information from 18 cases (4 patients from Spain and 14 from Chile), which have been published. ${ }^{6}$ At the time of the acute event (in 2013), the toxic substances responsible could not be detected by the AEMPS analysis. However, IOBA has now identified the presence of acids and alcohols, which perfectly explains the high rate of toxicity that caused severe retinal necrosis after a few minutes of contact with the substance. In all surgeries, perfluorocarbon liquids were used during surgery only, and the products had been removed before the surgery concluded.
Figure 2: Two months after successful retina detachment surgery

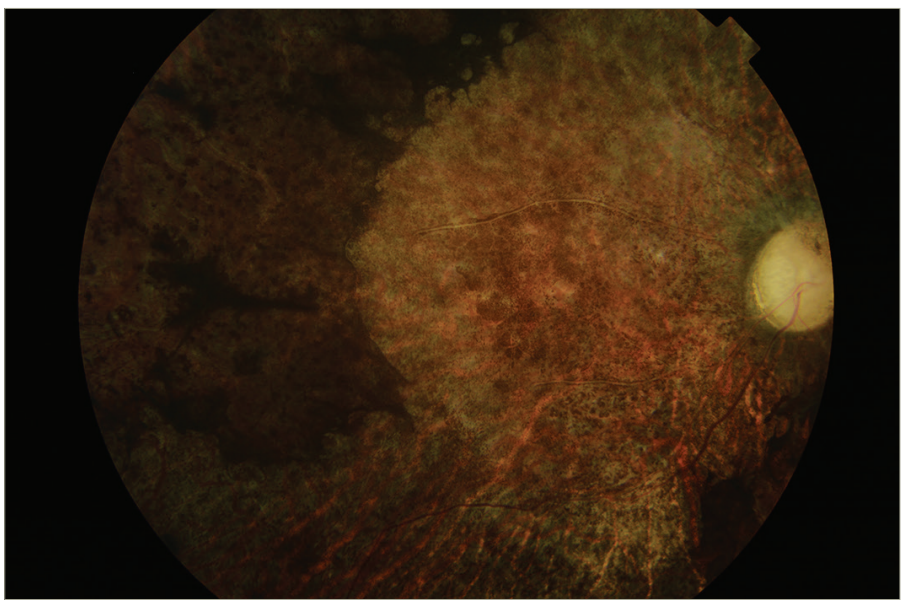

No light perception. Total optic nerve atrophy and retina and choroid atrophy in the posterior pole where perfluoro-octane was in contact during surgery.

By the end of 2014 and during 2015, several Spanish ophthalmologists began to report cases of acute blindness following correct use of AlaOcta ${ }^{\circledR}$, a perfluorocarbon (Alamedics GmbH, Dornstadt, Germany). Finally, 117 cases have been officially recognised by the AEMPS, and clinical pictures suggesting toxicity and toxic contaminants have been published by the IOBA. ${ }^{7}$ Suspicious clinical pictures were established by a committee of the Spanish Vitreo Retina Society (Figure 1 and Figure 2). ${ }^{\text {. }}$

In December 2016, a new alert from the AEMPS was issued; this time it related to four cases of acute blindness caused by a product called Bio-Octane Plus ${ }^{\circledast}$ (Biotech Ophthalmic PVT Ltd., Ahmadabad, India). This product was a mixture of perfluorocarbon liquids, and a highly harmful stannane derivate (bromotributyl stannane), was identified as the cause of toxicity. The clinical aspects and analytical results have been published. ${ }^{8}$

Subsequently, health alerts have been reported regarding other products, such as Perfluoron ${ }^{\circledast}$ (Alcon Laboratories, Inc., Fort Worth, TX, USA), Eftiar Octane ${ }^{\circledR}$ (DORC, Zuidland, The Netherlands), and others that have not been confirmed as toxic after analyses carried out by IOBA, as indicated by the AEMPS.

\section{The reaction of ophthalmologists}

Any healthcare professional is expected to immediately report possible adverse effects to their regulatory agency. This is how the effective surveillance system of many countries works. ${ }^{9}$

However, in the case of perfluorocarbon liquid toxicity, with the exception of Spain and several other countries, the surveillance system has not worked properly. The reasons are not clear, but there are some that may account for this. The denial of certain companies that their product could cause blindness, together with suggestions in the mass media of misuse of the products by retinologists, instigated fear among ophthalmologists of legal consequences and complaints from patients. In addition, different actions by certain manufacturers in several meetings attributed the toxicity to a purely Spanish problem. Finally, there has been certain resistance on the part of some medical devices agencies to admit that products with 
safety certificates-made in accordance with ISO standards and with the CE mark — could be the cause of serious problems.

Nevertheless, and thanks to the presence of IOBA members in different meetings and via publications, other professionals have started to publish their cases. ${ }^{10,11}$ As a result, we believe that the current attitude of ophthalmologists is that they are much more likely to report any possible adverse effect, which is a crucial point if one wants to prevent recurrence of this type of problem.

\section{The problem with ISO standards}

All the products affected by this terrible problem displayed certificates issued by notified bodies in which the products were apparently safe, and included cytotoxicity tests performed under the ISO standards (ISO 10993-1: 2009; ISO 10993-5: 2009; ISO 10993-12: 2012). However, the ISO standards do not exactly define any test conditions. Also, in those carried out by the companies affected by the cases of AlaOcta ${ }^{\circledR}$ and Bio Octane Plus ${ }^{\circledast}$, the tests performed by the notified bodies omitted two important points: that perfluorocarbon liquids are immiscible in water and that they are volatile substances. Consequently, our group has developed a direct method that takes these characteristics into account and which has been accepted by the AEMPS as a reference. ${ }^{12}$

These reasons, among others, are why we disagree with the new term used in the ISO standards: "ophthalmic implants". ${ }^{3}$ For any clinician, the term "ophthalmic implant" can mean anything from an intraocular lens to an orbital implant. This nomenclature does not facilitate comprehension of the information by ophthalmologists. In our opinion, incorporating ocular endotamponades, expandable gases, perfluorocarbon liquids, and silicone oils in the same ISO standard only serves to further complicate the understanding of the products by clinicians.

For this reason, a note from the Spanish Retina and Vitreous Society was submitted to the ISO Committee, of which we are members, recommending separate standards for each type of product. Unfortunately, our recommendations were not accepted in the final vote.

\section{What is the position of the manufacturers?}

There are variable positions of the manufacturers. Those who caused the problems ignored our requests for more information on the possible origin of the toxic contaminants; for example, where they obtained the raw product. We think this information is critical to avoid future problems.
Others have opted for the line of ultra-purification of the products, even proposing indices (e.g. $\mathrm{H}$ index) that mark the percentage of partially fluorinated compounds that eliminates any possibility of toxicity. ${ }^{13}$ However, this type of index has been rejected by other manufacturers. Although it may be a desirable kind of index, a direct relationship between $\mathrm{H}$ index and toxicity has not yet been demonstrated. ${ }^{14,15}$

Some companies seem to find it difficult to accept that there have been hundreds, probably thousands, of cases of blindness with these products (e.g. from toxic batches of AlaOcta $^{\circledR}$ more than 1,000 samples were distributed in Spain alone, although there is information only on 117 officially affected cases), and that a close collaboration between industry and clinicians is of paramount importance.

\section{What does the future hold?}

We trust that the European health authorities will be alert to this issue, and that the standards contained in the new guide for medical devicesnamely, MEDDEV 2.7.1: Clinical evaluation: guide for manufacturers and notified bodies under Directives 93/42/CEE and 90/385/EEC-will be developed. ${ }^{16}$ The guide, which should be implemented in 2021, includes substantial modifications that affect all medical devices and a specific section for serious adverse-event reporting.

However, we believe that the solution also involves developing new products that can replace those currently being used; however, it is obvious that the current products cannot be improved in some cases. For example, silicone oil for intraocular use was introduced in the 1960s by Paul Cibis, and it continues to be a source of problems. With purer products the problems will surely decrease; however, the fundamental issue is that a lipophilic substance cannot be in contact with intraocular tissues for a long period of time because it dissolves the lipids of cell membranes. Consequently, alternatives should be sought.17,18

However, it is also essential that clinicians report all possible adverse effects, and that companies pay attention to, not only defending their position in the market, but also incorporating a transparency policy that makes them react quickly to any possible problem and that seeks a more honest understanding with clinicians. Currently, only the combination of products that are sufficiently pure from a chemical point of view, and biological tests appropriate to the nature of the substances, can help to improve the confidence of ophthalmologists in these types of products. $\square$
1. Januschowski K, Irigoyen C, Pastor JC, et al. Retinal toxicity of medical devices used during vitreoretinal surgery: a critical overview. Ophthalmologica. 2018;240:236-43.

2. Houede, P. [German lab denies its product caused vision loss in patients]. [Article in Spanish]. 2015. Available at: https:// es.noticias.yahoo.com/dos-pacientes-tratados-con-productosospechoso-pierden-la-184239743.html?guccounter $=1$ \&guce referrer=aHROCHM6Ly93d3cuZ29VZ2xlLmNvbS8\&guce_referrer sig=AQAAAHcx90ndhsch-SFuJRSKCARO2-DO-45nJw6hQDFSyLB2PC7CNOCTRUOAI89UhMTTJJ8ORJUREJXUQZQGOWEbWU2yUOMCWL b5NOcEb79uyORbpaVChpFKuy7UerjTdZ5E5QB58XZZ_yuL_Cn2 bJI6YIAB BTYbr1XSVEhKVA-zs (accessed January 11, 2021).

3. ISO/FDIS 16672.2. Ophthalmic implants—ocular endotamponades. 2020. Available at: www.iso.org/standard/70806.html (accessed January 11, 2021).

4. Chang S, Sparrow JR, Iwamoto T, et al. Experimental studies of tolerance to intravitreal perfluoro-n-octane liquid. Retina. 1991;11:367-74.

5. Figueroa MS, Casas DR. Inflammation induced by perfluorocarbon liquid: intra- and postoperative use. Biomed Res Int. 2014;2014:907816.
6. Coco-Martin RM, Andrés-Iglesias C, Srivastava GK, et al. Intraocular toxicity caused by MEROCTANE perfluorocarbon liquid. Sci Rep. 2021;11(1):599.

7. Pastor JC, COCO RM, Fernandez-Bueno I, et al. Acute retinal damage after using a toxic perfluoro-octane for vitreo-retinal surgery. Retina. 2017;37:1140-51

8. Coco RM, Srivastava GK, Andrés-Iglesias C, et al. Acute retinal toxicity associated with a mixture of perfluorooctane and perfluorohexyloctane: failure of another indirect cytotoxicity analysis. Br J Ophthalmol. 2019:103:49-54.

9. European Commission. Medicinal products. Available at: https:// ec.europa.eu/health/human-use/pharmacovigilance_en (accessed January 11, 2021)

10. Méndez-Martínez S, Calvo P, Rodriguez-Marco NA, et al. Blindness related to presumed retinal toxicity after using perfluorocarbon liquid during vitreoretinal surgery. Retina. 2018;38:1856-64.

11. Tobalem SJ, Weinberger A, Kropp M, et al. Chorioretinal toxicity of perfluorooctane (Ala Octa): Results from 48 surgical procedures in Geneva. Am J Ophthalmol. 2020;218:28-39.

12. Srivastava GK, Alonso-Alonso ML, Fernandez-Bueno I, et al. Comparison between direct contact and extract exposure methods for PFO cytotoxicity evaluation. Sci Rep. 2018;8:1425.

13. Menz DH, Feltgen $\mathrm{N}$, Menz $\mathrm{H}$, et al. How to ward off retinal toxicity of perfluorooctane and other perfluorocarbon liquids? Invest Ophthalmol Vis Sci. 2018;59:4841-6.

14. Ruzza P, Gatto C, Ragazzi E, et al. H-content is not predictive of perfluorocarbon ocular endotamponade cytotoxicity in vitro. ACS Omega. 2019;4:13481-7.

15. Srivastava GK, Andrés-Iglesias C, Coco RM, et al. Chemical compounds causing severe acute toxicity in heavy liquids used for intraocular surgery. Regul Toxicol Pharmacol. 2020;110:104527.

16. European Commission. Guidelines on Medical Devices. Clinical Evaluation: A Guide for Manufacturers and Notified Bodies Under Directives 93/42/EEC and 90/385/EEC. Available at: https:// ec.europa.eu/health/md_sector/current_directives_en (accessed January 25,2021$)$.

17. Dresp JH. Benchmarking different brands of silicone oils. Graefes Arch Clin Exp Ophthalmol. 2021;259:13-20. Erratum in: Graefes Arch Clin Exp Ophthalmol. 2021;259:273-4.

18. Pastor Jimeno JC, de la Rúa ER, Fernández Martínez I, et al. Lipophilic substances in intraocular silicone oil. Am J Ophthalmol. 2007;143:707-9. 